\title{
Statically Downscaling using different Representative Concentration Pass ways of Emission Scenario; in the Case Wolikite, South West Ethiopia
}

\author{
Moges Molla* \\ Ethiopian Environment and Forest Research Institute, Ethiopia
}

Submission: July 24, 2020; Published: August 07, 2020

*Corresponding author: Moges Molla, Ethiopian Environment and Forest Research Institute, Hawassa Center, Hawassa, Ethiopia.

\begin{abstract}
Nowadays the sign of climate change and its impact is revealing on different natural and manmade systems, in one or other ways. This study mainly deals to develop future climate change scenario for Wolikite using statistically downscaling of large-scale climate variables. Projection of the future climate variables is done by using Global Circulation Model (GCM) which is considered as the most advanced tool for estimating the future climatic condition. The Statistical Downscaling Model (SDSM) is used to downscale present and future daily precipitation and temperature using observed station data. Three future emission scenarios, RCP2.6 (low emission), RCP4.5 (intermediate emission) and RCP8.5 (high emission) are considered for three 30 years periods for near term (2020-2039), 2020's mid-term (2040-2059), 2050's end of century (2080-2099), 2080's. The average annual minimum temperature will be increased by $3.3^{\circ} \mathrm{C}, 5.3^{\circ} \mathrm{C}$ and $9.0^{\circ} \mathrm{C}$ for rcp2.6, rcp 4.5 and rcp8.5 scenario respectively towards the end of this century. Similarly, annual maximum temperature will be $7.0^{\circ} \mathrm{C}, 6.0^{\circ} \mathrm{C}$, and $8.0^{\circ} \mathrm{C}$. Under RCP2.6 the mean temperature increases by approximately $2^{\circ} \mathrm{C}$ at the end of the century relative to the baseline period. For RCP 4.5 , which represents the moderate scenario, the projected increase in temperature is around $2.9^{\circ} \mathrm{C}$. The ensemble models are broadly consistent in indicating the shortening the main rain seasons that means monomial rainfall shrinks and ranging from over eight months of rain to only three months (JAS) under all RCPs for all time horizon the station which requires water harvesting, effective and efficient utilization of water resource.
\end{abstract}

Keywords: Climate; Emission; Scenario; RCPs; SDSM

\section{Introduction}

General Circulation Models (GCMs), which are widely used nowadays to simulate future climate scenarios. There are different techniques for down scaling large scale GCM outputs to small scale resolutions to use in other models. All the available techniques and rationale of downscaling are categorized under two broad groups, namely dynamic downscaling and statistical downscaling [1-3]. The dynamic downscaling is performed by Regional Climate Models (RCMs) or Limited Area Models (LAMs) at $0.5^{\circ} \times 0.5^{\circ}$ or an even higher resolution that parameterizes the atmospheric processes. The RCMs utilize large scale and lateral boundary conditions from GCMs to produce higher resolution outputs that demands high competition time. The statistical downscaling techniques involve developing quantitative relationships between large scale atmospheric variables (the predictors) and local surface variables (the predictands).

Pragmatic downscaling starts with the premise that the regional climate is the result of interplay of the overall atmospheric or oceanic circulation as well as of regional topography, land-sea distribution and land use. As such empirical downscaling seeks to drive the local scale information from the larger scale through inference from the cross-scale relationship using some random or deterministic functions. In most cases, the regional climate is seen as random process conditioned up on a driving large scale climate regime. Therefore, the confidence that may be placed in downscaled climate change information is foremost dependent on the validity of the large -scale field from GCM. For instance, derived variables (not fundamental to the GCM physics but derived from the physics) such as precipitation are usually not robust information at the regional and local scale [4]. Conversely, tropospheric quantities like temperature or geo-potential height are intrinsic parameters of the GCM physics and are more skillfully represented by GCM.

\section{Downscaling Methods and Tools}

The general circulation models (GCMs) used to simulate and project future climate with forcing by greenhouse gases and 
aerosols, typically dived the atmosphere and ocean in to horizontal grid with a resolution of $2^{\circ}$ latitude by $4^{\circ}$ longitude, with 10 to 20 layers in the vertical. In general, most GCMs simulate global and continental scale processes in detail and provide a reasonable accurate representation of the average planetary climate. Over the past decade ,the sophistication of such model has increased and their ability to simulate present and past global and continental scale climate has substantially improved .Nevertheless, while GCM demonstrates significant skill at the continental and hemispherical scale and incorporate a large portion of the complexity of the global system, they are inherently unable to represent local subgrid scale features and dynamics, such as local topographical feature and convective cloud process [5]. Moreover, GCM were not designed for climate change impact studies and do not provide a direct estimation of the hydrological response to climate change. For example, assessment of future river flow may require (subscenarios) daily precipitation in the catchment even at station scales. Therefore, there is a need to convert GCM out put into at least a reliable daily rainfall series at the scale of the watershed to which the hydrological impact is going to be investigated. The method used to covert GCM output into local meteorological variables required for reliable hydrological modeling are usually referred to as downscaling techniques. There are two categories of climate downscaling methods namely dynamic downscaling and statistical downscaling $[5,6]$.

According to [7] regardless of human action in the immediate future, the effects of climate change will persist for centuries. Along with the increase in mean global temperatures, precipitation, humidity, and cloudiness are also expected to increase. Globally averaged surface air temperatures are forecast to increase by $1.4^{\circ} \mathrm{C}$ to $5.8^{\circ} \mathrm{C}$ by the year $2100[7,8]$. The frequency and intensity of extreme weather and climatic events will increase in many regions. As such, projected increases in precipitation may not be evenly distributed throughout the year. Rather, precipitation may occur in the form of more frequent intense storm events, which will result in high runoff levels and increased risks of flooding [9]. Higher temperatures will increase evapotranspiration. [10] Reviewed the current state of climate change science, reporting that mean global surface temperatures increased by about $0.7^{\circ} \mathrm{C}$ during the 20 th century, with $0.4^{\circ} \mathrm{C}$ to $0.5^{\circ} \mathrm{C}$ of this change occurring since 1970 . Historical precipitation trends are much less clear, because spatial and temporal distributions are characteristically much more variable than those for temperature. Available data suggest recent increases of $0.5 \%-1.0 \%$ per decade in mean annual precipitation on land in the mid- to high latitude regions of the northern hemisphere, with slight decreases in the subtropics [9,11-13]. The Atlantic hurricanes of 2004-2005 and a general trend of increasing storm damage.

Climate data encompass both point-based data (for specific climate stations) and gridded data (estimated from observations made at climate stations), as well as historical time series, climate normal (averages calculated over specified 30-year periods), and scenarios of past and future climate developed from GCM simulations.

The IPCC [8] proposed that simulations of the impacts of climate change should be based on a suite of GHG emissions scenarios, each of which would represent a plausible future "story" of human population change and economic growth. These are known as the special report on emissions scenarios [14]. The various groups working on GCMs around the globe have all been expected to carry out simulation experiments "forced" by some or all of these SRES scenarios.

\section{The difference between RCPs and previous scenarios}

In preparation for the Fifth Assessment Report (AR5), researchers developed a new approach for creating and using scenarios in climate change research. This new approach was motivated by the changing information needs of policy makers. For example the increasing interest in exploring different approaches to achieving specific climate change targets (such as limiting change to $2^{\circ} \mathrm{C}$ ), and growing interest in a "risk management" approach that combines reductions in emissions and adaptation to reduce climate change damages.

Scientific advances also dictated the need for new scenarios. Since the Fourth Assessment Report (AR4) important improvements in climate models have been made. As the climate models became more sophisticated, more detailed input was needed. Simultaneously, models that are used in the production of scenarios have improved and more advanced input can therefore be provided $[15,16]$.

a) RCP 8.5 - High emissions: This RCP is consistent with a future with no policy changes to reduce emissions. It was developed by the International Institute for Applied System Analysis in Austria and is characterized by increasing greenhouse gas emissions that lead to high greenhouse gas concentrations over time comparable SRES scenario A1 F1. This future is consistent with: Three times today's CO2 emissions by 2100, Rapid increase in methane emissions, Increased use of croplands and grassland which is driven by an increase in population, $\mathrm{A}$ world population of 12 billion by 2100 , Lower rate of technology development, Heavy reliance on fossil fuels, High energy intensity and no implementation of climate policies $[15,16]$.

b) RCP 6 - Intermediate emissions: This RCP is developed by the National Institute for Environmental Studies in Japan. Radiative forcing is stabilized shortly after year 2100 , which is consistent with the application of a range of technologies and strategies for reducing greenhouse gas emissions. Comparable SRES scenario: B2. This future is consistent with:- Heavy reliance on fossil fuels, Intermediate energy intensity, Increasing use of croplands and declining use of grasslands, Stable methane emissions, and $\mathrm{CO}_{2}$ emissions peak in 2060 at 75 per cent above today's levels, then decline to 25 per cent above today $[15,16]$. 
c) RCP 4.5 - Intermediate emissions: This RCP is developed by the Pacific Northwest National Laboratory in the US. Here radiative forcing is stabilized shortly after year 2100, consistent with a future with relatively ambitious emissions reductions comparable SRES scenario B1. This future is consistent with: Lower energy intensity, Strong reforestation programmes, Decreasing use of croplands and grasslands due to yield increases and dietary changes, Stringent climate policies, Stable methane emissions and $\mathrm{CO} 2$ emissions increase only slightly before decline commences around 2040 [15,16].

d) RCP 2.6 - Low emissions: This RCP is developed by PBL Netherlands Environmental Assessment Agency. Here radiative forcing reaches $3.1 \mathrm{~W} / \mathrm{m}^{2}$ before it returns to $2.6 \mathrm{~W} / \mathrm{m}^{2}$ by 2100 . In order to reach such forcing levels, ambitious greenhouse gas emissions reductions would be required over time. Comparable SRES scenario: None. This future would require: Declining use of oil, Low energy intensity, A world population of 9 billion by year
2100, Use of croplands increase due to bio-energy production, More intensive animal husbandry, Methane emissions reduced by 40 per cent, $\mathrm{CO}_{2}$ emissions stay at today's level until 2020, then decline and become negative in 2100 and $\mathrm{CO}_{2}$ concentrations peak around 2050 , followed by a modest decline to around 400 ppm by $2100[15,16]$.

Figure 1 illustrates the general approach of downscaling; firstly statistical downscaling is analogous to the "model output statistics" and "perfect prog" approaches used for short-range numerical weather prediction .Secondly, Regional Climate Model (RCM) simulates sub-GCM grid scale climate features dynamically using time -varying atmospheric conditions supplied by a GCM bounding a specific domain. Both approaches will continue to play a significant role in the assessment of potential climate change impacts arising from future increase in greenhouse gas concentration. The SDSM is the first tool of its type freely offered to the broader climate change impacts community.

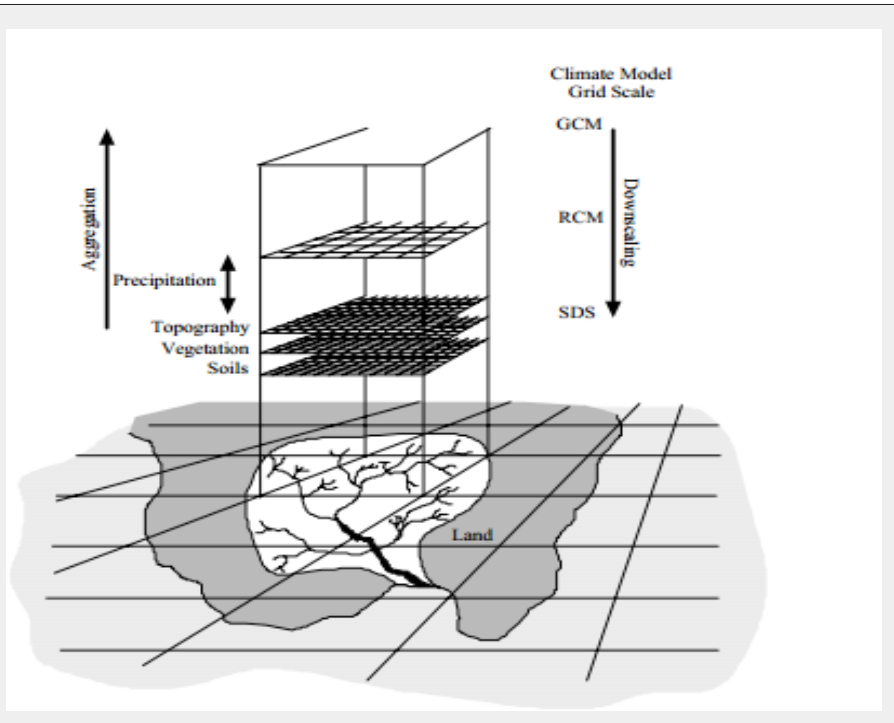

Figure 1: A schematic illustrating the general approach of downscaling. (Source SDSM manual version 4.2).

\section{GCMs and Statistical Down Scaling Methods}

Use of all available GCMs and emission scenario will result in a better understanding of climate change. However, due to the limited amount time available to complete the present study, this research deals with the output from CanESM2 model for RCP scenarios. Canadian Earth System Model CanESM2 combines the CanCM4 model and the terrestrial carbon cycle based on the Canadian Terrestrial Ecosystem Model (CTEM) which models the land-atmosphere carbon exchange. The concentrations of greenhouse gases and solar variability are based on the CMIP5 recommendations. In addition, the effects of volcanic eruptions are included. CanESM2 is applied in this study because the model is widely applied in many climate change impact studies and it provides large scale daily predictor variables which can be used for Statistical Downscaling Model (SDSM) [16,17].

SDSM which is designed to downscale climate information from coarse resolution of GCMs to local or site level was applied here to downscale the precipitation, maximum and minimum temperatures for the study area. SDSM uses linear regression techniques between predictor and predictand to produce multiple realizations (ensembles) of synthetic daily weather sequences. The predictor variables provide daily information about large scale atmosphere condition, while the predict and described the condition at the site level. The main reasons to apply the SDSM model for the study are; it is widely applied in many regions of the world over a range of different climatic condition, It can be runs on 
PC-based systems and has been tested on Windows 98/NT/2000/ $\mathrm{XP}$, The availability of the software (i.e. new users can register and download freely the software package at https://co-public. lboor.ac.uk/cocwd/SDSM/), Compared to other downscaling methods, the knowledge of atmospheric chemistry required by the SDSM is less, The required time for simulating the surface weather parameter is low and the ability of the model to permit risk/uncertainty analyses by using the generated ensembles [18] (Table 1).

Table 1: Relative strength and weakness of statistical and dynamical downscaling.

\begin{tabular}{|c|c|c|}
\hline & Statistical Downscaling & Dynamical Downscaling \\
\hline 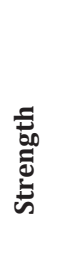 & $\begin{array}{l}\text { - Station-scale climate information from GCM-scale output. } \\
\text { Cheap, computationally undemanding and readily transferable. } \\
\text { Ensembles of climate scenarios permit risk/ uncertainty analyses. } \\
\text { Applicable to 'exotic' predictands such as air quality and wave } \\
\text { heights. }\end{array}$ & $\begin{array}{l}\text { 10-50km resolution climate information from GCM- } \\
\text { scale output. } \\
\text { - Respond in physically consistent ways to different } \\
\text { external forcing's. } \\
\text { - Resolve atmospheric processes such as orographic } \\
\text { Precipitation. } \\
\text { • Consistency with GCM. }\end{array}$ \\
\hline 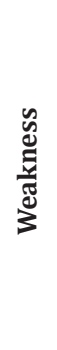 & $\begin{array}{l}\text { Dependent on the realism of GCM boundary forcing } \\
\text { - Choice of domain size and location affects results. } \\
\text { - Requires high quality data for model calibration. } \\
\text { - Predictor-predictand relationships are often non- } \\
\text { Stationary. } \\
\text { - Choice of predictor variables affects results. } \\
\text { - Choice of empirical transfer scheme affects results. } \\
\text { - Low-frequency climate variability problematic. } \\
\text { - Always applied off-line, therefore, results do not } \\
\text { feedback into the host GCM. }\end{array}$ & $\begin{array}{l}\text { Dependent on the realism of GCM boundary forcing } \\
\text { - Choice of domain size and location affects results. } \\
\text { - Requires significant computing resources. } \\
\text { - Ensembles of climate scenarios seldom produced. } \\
\text { - Initial boundary conditions affect results. } \\
\text { - Choice of cloud/ convection scheme affects } \\
\text { (precipitation) results. } \\
\text { - Not readily transferred to new regions or domains. } \\
\text { - Typically applied off-line, therefore results do not } \\
\text { always feedback into the host GCM. }\end{array}$ \\
\hline
\end{tabular}

(Source SDSM manual version 4.2).

\section{SDSM model setup}

\section{Predictor files:}

The SDSM predictor data files for the CanESM2 model are downloaded from the Canadian Institute for Climate Studies. The predictor variables of CanESM2 are provided on a grid box by grid box basis of size $2.5^{\circ}$ latitude $\times 3.75^{\circ}$ longitude. To represent the station data from the nearest grid box (BOX_014X_35Y) were downloaded from CICS for wolikite meteorological stations. This predictor is found in zip file format. When the zip file is opened the following climatic parameters are found.

a) NCEP_1961-2005: this directory contains 44 years of daily observed predictors' data, derived from the NCEP reanalysis, and normalized (with respect to the mean and standard deviation) over the complete 1961-1990 period. b) CanESM2_historical_1961_2005: this directory contains 44 years of daily GCM predictor's data, derived from the CanEsm2 historical data experiment, and normalized over the 1961-1990 period.

c) CanESM2_rcp2.6_2006_2100: this directory contains 94 year of daily GCM predictor data, derived from the RCP2.6 experiment, and normalized over the 1961-1990 period.

d) CanESM2_rcp45_2006_2100: this directory contains 94 year of daily GCM predictor data, derived from the RCP4.5 experiment, and normalized over the 1961-1990 period.

e) CanESM2_rcp8.5_2006_2100: this directory contains 94 year of daily GCM predictor data, derived from the RCP4.5 experiment, and normalized over the 1961-1990 period.

NCEP data which are re-analysis sets from the National Center for Environmental Prediction was re-gridded to match 
with the grid system of CanESM2. These data are used for model calibration. Both NCEP and CanESM2 data have daily predictors. There exist 26 predictor's variables in both NCEP and CanESM2 which used for analysis [18].

At recent decade, the problem of climate variability and climate change, due to anthropogenic as well as natural processes, has come with daily bad news [19]. Drought, rain fall delay, fire damage and heavy and unexpected rain fall are climate related hazards that mainly faced and also total crop loss, reduced yield, reduced seeding quality, delayed maturity and increased crop pest/disease are the major climate impacts, [20].

Finally, this specific point location study using statistical downscaling model is aimed to fill the gap of the climate information of temperature and Precipitation, on the other hand, remained fairly stable over the last 50 years when averaged over the country. However, the spatial and temporal variability of precipitation is high thus large-scale trends do not necessarily reflect local conditions thus statistical down scaling provide the future monthly precipitation and temperature climate information under different RCPs for 2020's, 2050's and 2080's time horizon.

\section{Materials and Methods}

\section{Site description}

Wolkite the administrative center of the Gurage Zone of the Southern Nations, Nationalities and Peoples' Region (SNNPR), this town has a latitude and longitude of $8^{\circ} 17^{\prime} \mathrm{N} 37^{\circ} 47^{\prime} \mathrm{E}$ and an elevation between 1910 and 1935 meters above sea level, is in the part of the nine regions of Ethiopia.

\section{Research design}

The observed temperature and precipitation data of the station was obtained from national Meteorology Agency. The NMA provide statistical dataset of daily or monthly precipitation and temperature. These data covering form the period of 1988 to 2018. After collecting the necessary data filling of missed data and quality checking was be made. GCM have been developed to simulate the present climate and have been used to predict future climatic change but GCM are at high resolution and there need to be downscale the results from such models to individual sites or localities for impact studies using SDSM. Atmospheric large scale variables (CanESM2 Predictors) was downloaded from IPCC's Fifth Assessment Report (AR5) CMIP5/ Coupled Model Intercomparison Project, Phase 5 (CMIP5)/ a collaborative climate modeling process coordinated by the World Climate Research Programme (WCRP).

The second generation of Earth System Model CanESM2 is the fourth generation coupled global climate model developed by the Canadian Centre for Climate Modelling and Analysis (CCCma) of Environment Canada (http://climate-scenarios.canada. $\mathrm{ca} /$ ?page=pred-canesm2). SDSM permits the spatial downscaling of daily predictor-predictand relationships using multiple linear regression techniques. The predictor variables provide daily information concerning the large-scale state of the atmosphere, whilst the predictand describes conditions at the site scale.

\section{SDSM description}

The first step before model calibration was quality control using SDSM through identification of gross data errors, missing data codes and outliers to get the appropriate quality data. The screening Predictor variables will be done by trial and error procedure for model calibration. Using the partial correlations statistics, predictors which showed the strongest association with the predictand will be selected. Assembly and calibration of statistical downscaling model(s) the large-scale predictor variables identified are used in the determination of multiple linear regression relationships between these variables and the local station data. Then SDSM manual procedure will be followed to generate climate scenario for the basins.

\section{Data source}

Observed daily precipitation and maximum and minimum temperatures data will be obtained from weather stations located in or near the watershed. National Centre for Environmental Prediction (NCEP) data will be generated for missing data filling and GCM-derived predictors will be generated form global data base. Climate data was downscaled using SDSM. The data was analyzed and tested using trend analysis Man Kandell.

\section{Screening of Potential Downscaling Variables}

Screening of the potential predictors for the selected predictand (i.e. observed precipitation, minimum and maximum temperature) were used to select the appropriate downscaling predictors for model calibration and the most crucial and decisive part in statistical downscaling model. Identifying an appropriate large-scale gridded predictor's result in good correlation between observed and downscaled climate variables during model calibration and scenario generation. The recommended methods for screening the potential predictors is starting the processes by selecting seven or eight predictor at a time and analyze their explained variance, then select those predictor which has higher explained variance (The significance level which tests the significance of predictor-predictand correlation was set to the default $\mathrm{P}<0.05$ ) and drop the rest.

For the selected predictor analyze or calculate their correlation matrix with the observed predictand, this statistics identify the amount of explanatory power of the predictor to explain the predictand and finally the scatter plot is carried out in order to identify the nature of the association (linear, non-linear, 
etc.), whether or not data transformation(s) may be needed, and the importance of outliers. This procedure is repeated by holding those predictors which passé the above criteria and add new predictors from the reset of available predictors.

\section{SDSM Model Calibration, Validation and Scenario}

\section{Generation}

The model calibration operation takes a selected predictand along with a set of predictors variables and computes the parameters of multiple regression equations via an optimization algorithm (either dual simplex of ordinary least squares). There are options in SDSM model structure to perform calibration process either monthly, seasonally, or annual time scale. Selecting one of these model type decide how the regression parameters are developed (for example if a model type monthly is selected, then the model develops one regression equation for the whole months and if annul model type is selected again one regression equation is developed for the whole one year and so on). For this study among the total period length of 1988-2003, 15 years of daily data was used for model calibration and the rest 15 years
(2004-2018) daily data was used for model validation using a monthly model type.

The Weather Generator operation generates ensembles (up to a maximum of 100) of synthetic daily weather series given observed (or NCEP re-analysis) atmospheric predictor variables. The procedure enables the verification of calibrated models (using independent data) and the synthesis of artificial time series for present climate conditions.

The Scenario Generator operation produces ensembles of synthetic daily weather series from the starting of the baseline period to the end of the next century(1961-2100) for a given daily atmospheric predictor variables supplied by a GCM (either under present or future greenhouse gas forcing). This function is identical to that of the Weather Generator operation in all respects except that it may be necessary to specify a different convention for model dates and source directory for predictor variables.

The structure and operations of SDSM can be best described with respect to seven tasks as indicated in bold box in the following Figure 2 [18].

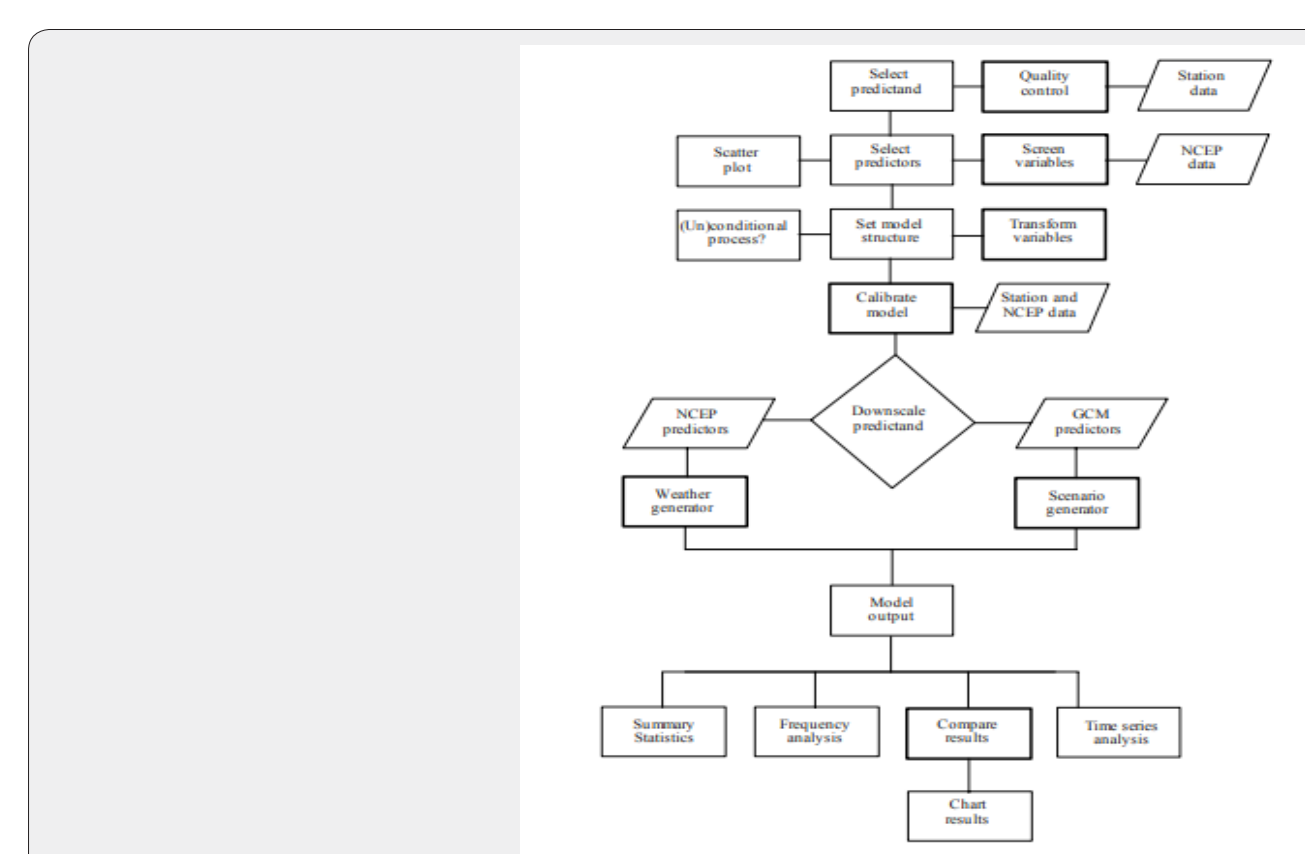

Figure 2: SDSM (version 4.2) Climate scenario generations.

(Source SDSM manual version 4.2).

\section{Results and Discussion}

\section{Observed and downscaled monthly mean temperature and Precipitation}

\section{Minimum temperature}

The monthly minimum temperature downscaled for NCEP in the baseline period for Wolkite meteorological station is shown in Figure 3.
The result of downscaling minimum temperature indicates that there is less agreement between observed and simulated minimum temperature compared to nearest meteorological station minimum temperature this is due to less quality of station data. As shown in Figure 4: it was also found that, during the month of May and Jun the model error is negligible. However, for the rest of the months the model overestimates. The model error in each month is less than the projected temperature change in the future. 


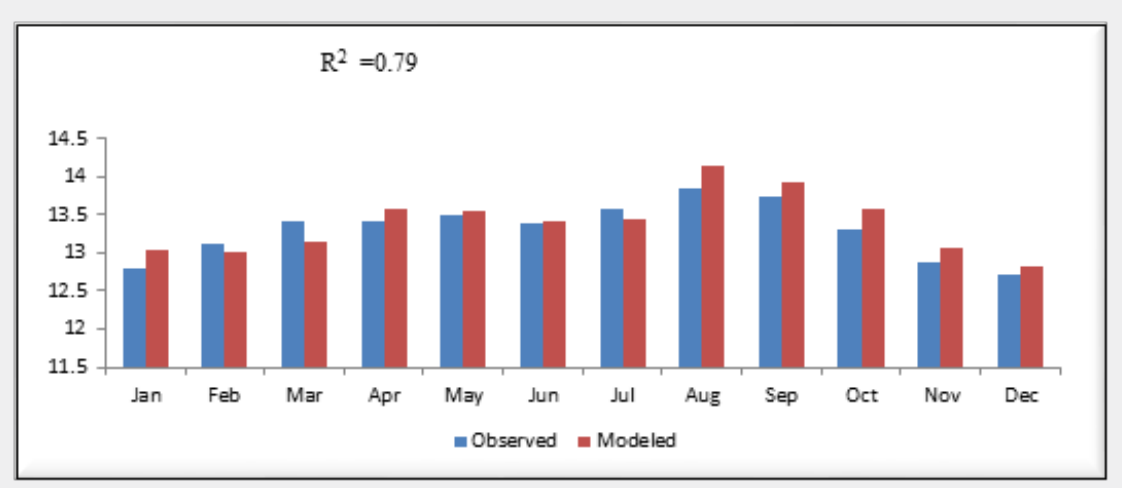

Figure 3: Comparison of observed and predicted mean minimum monthly temperatures for the period (1988-2003) at wolkite station.

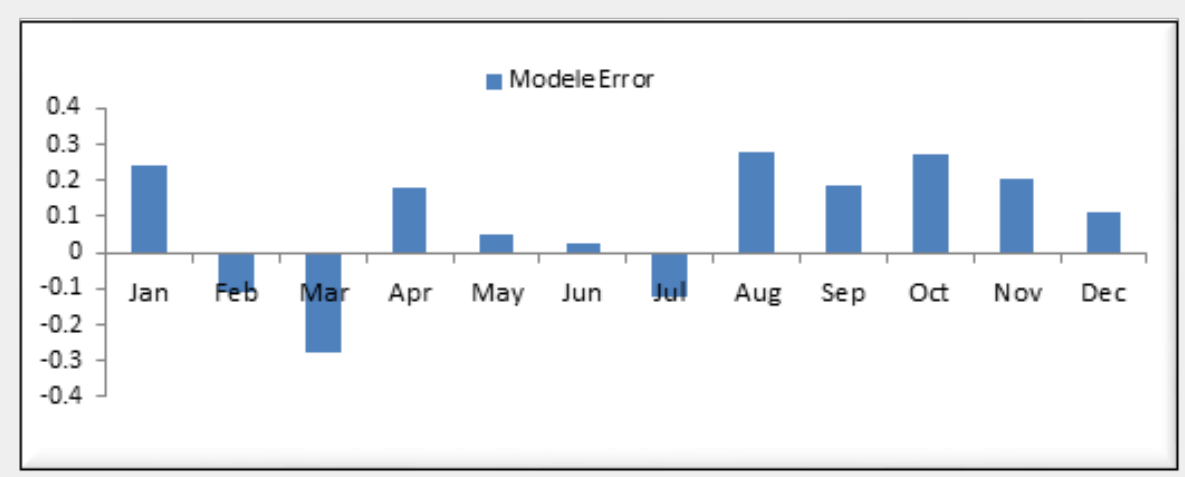

Figure 4: Absolute model errors in estimate of monthly minimum temperature.

\section{Maximum temperature}

The monthly maximum temperature downscaled for NCEP in the baseline period is shown in Figure 5.

The result of downscaling maximum temperature indicates that there is a very good agreement between observed and simulated maximum temperature. However as shown in Figure 5 the model underestimates maximum temperature during the month Jan and Nov. however the model overestimates for the rest of the months except Jan and Nov.

\section{Precipitation}

As shown in Figure 7 below the result of downscaling Wolkite station precipitation indicates that there is an excellent agreement between observed and simulated precipitation this is due to good quality of data.

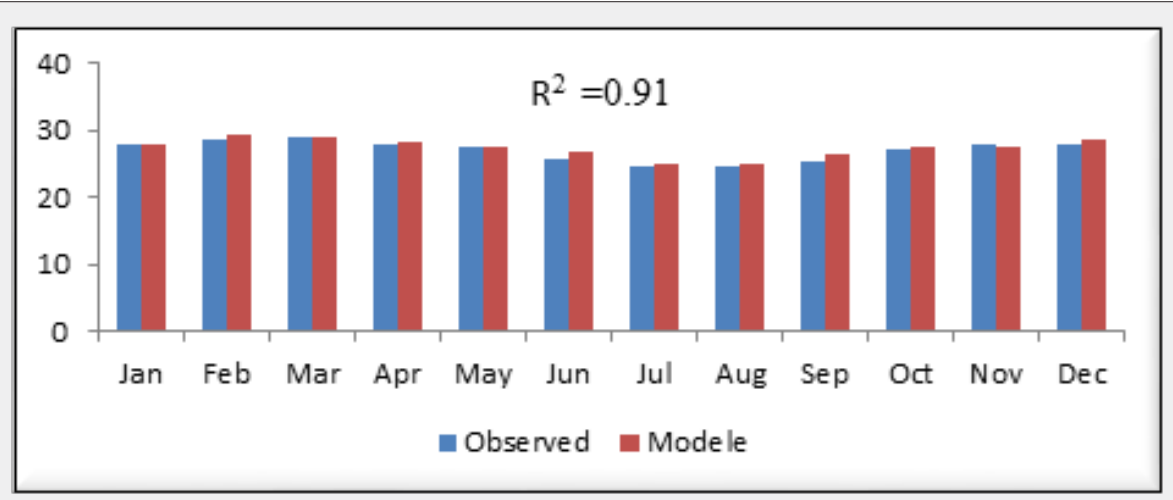

Figure 5: Observed and downscaled monthly mean maximum temperature for Wolkite meteorological station. 


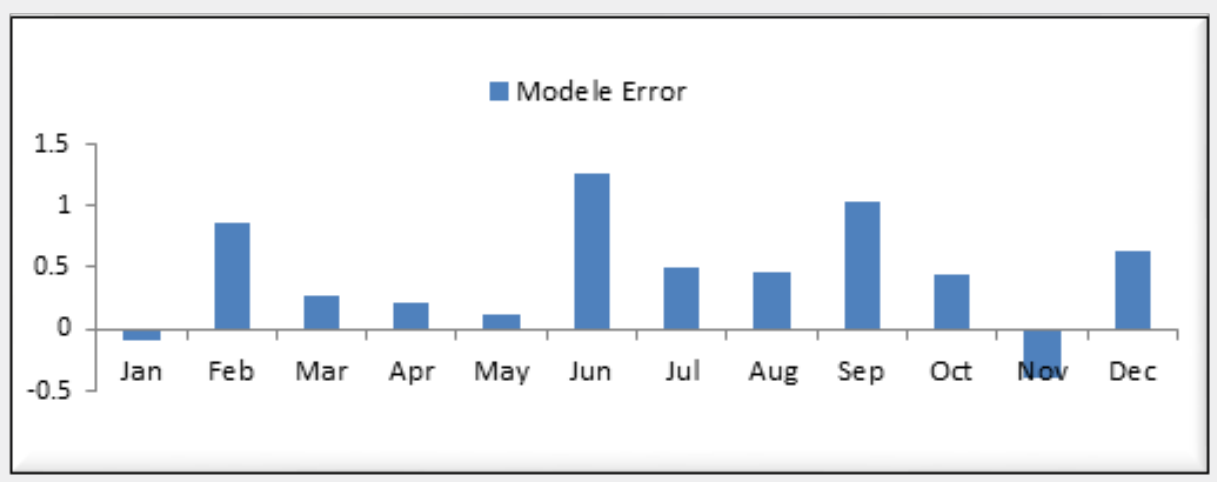

Figure 6: Absolute model error in estimate of monthly maximum temperature.

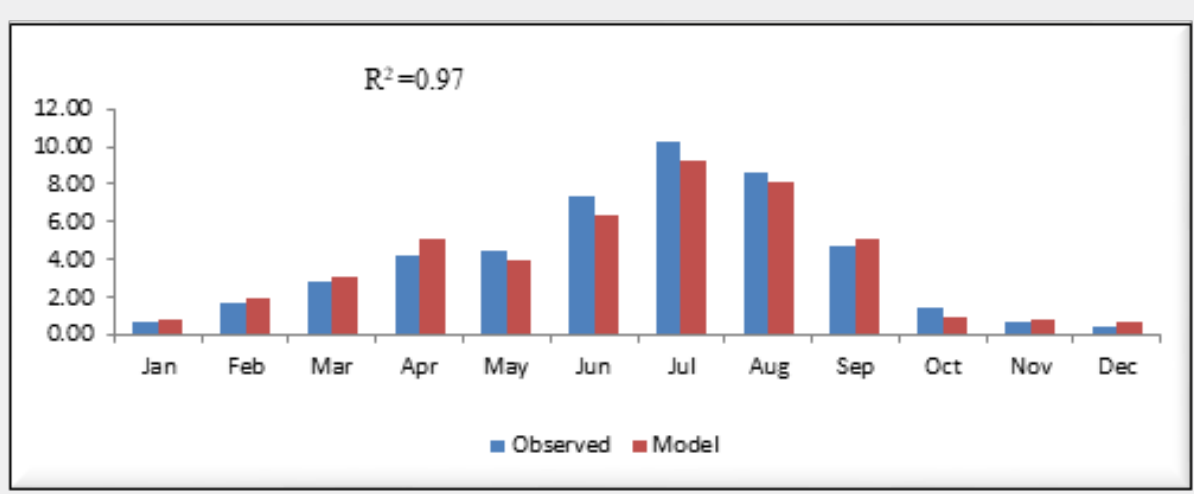

Figure 7: Downscaled and observed mean monthly precipitation (1988-2003).

The downscaled precipitation underestimates during the month of May, Jun, Jul, Aug and Oct and overestimates for the remaining months.

Results indicate that the models replicate observed intermonthly and inter-annual variability faithfully, achieving maximum correlations of the order of 0.98 for temperature (Figure 7) and 0.79 for rainfall (Figure 8) leaving residuals whose variance is much less than the variance of the raw data. The performance of the SDSM is almost as very good over the verification period as it is over the calibration period, indicating that the empirical model has not been over-fit to the data. Moreover, calibration and validation of maximum and minimum temperature result show better correlation coefficient as compared to rainfall.

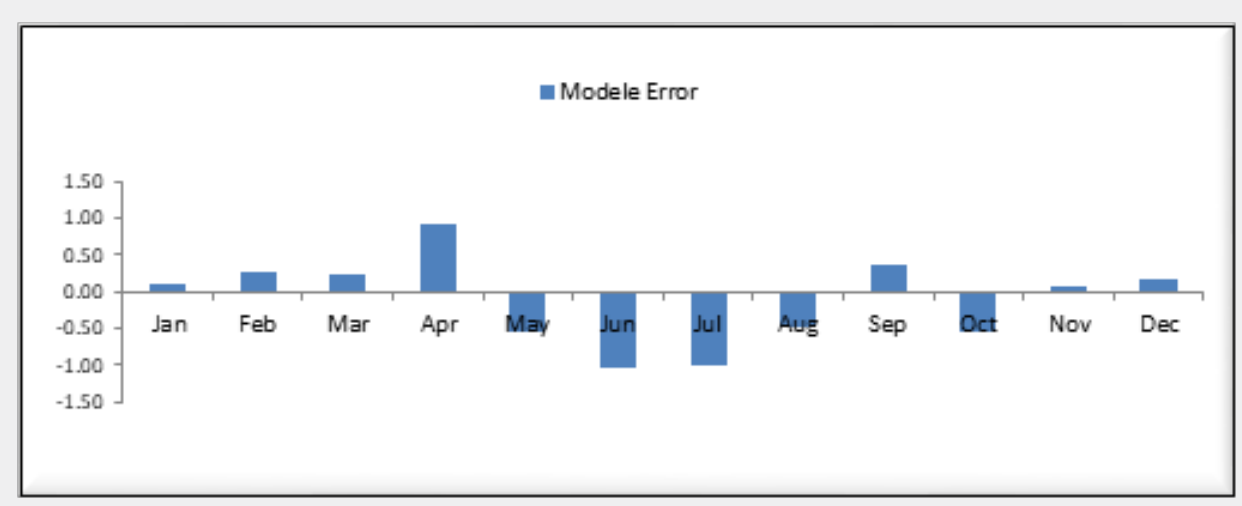

Figure 8: Absolute model errors for the downscaled precipitation. 


\section{Anomalies of Climate variable under different RCPs emission scenarios}

\section{Minimum temperature anomaly}

The Figure 9 shows that a negative anomaly will be observed in 2020's and 2080's time horizon under RCP 2.6 for the months
JJAS and FMA respectively.

As indicated Figure 10 \& 11 below most of dry months revealed that a positive anomaly in the 2050's time horizon. Under worst scenario (RCP8.5) only April and July show negative anomaly for time horizon of 2080's this indicates that the observed minimum temperature was cooler than the long- term mean value.

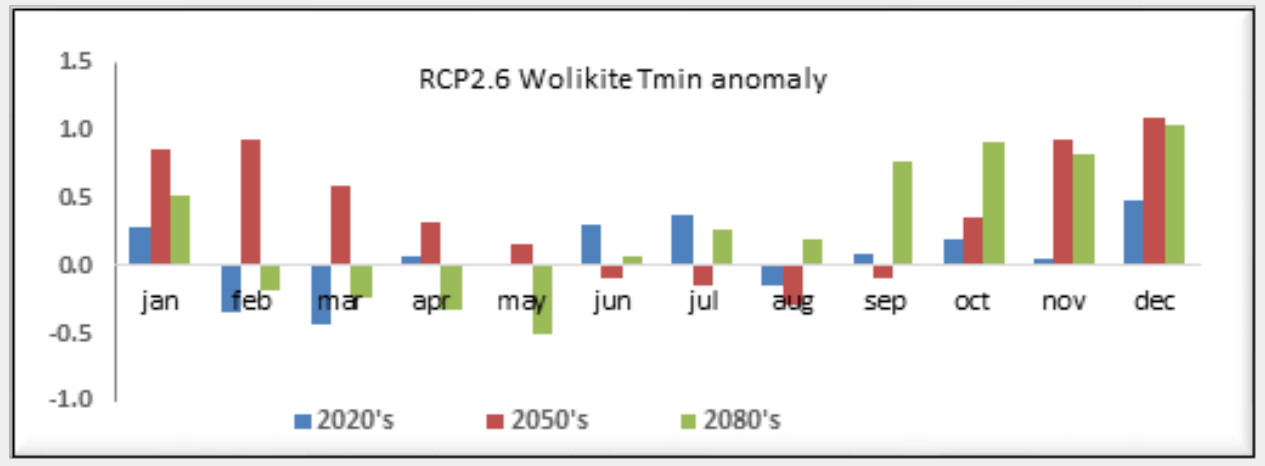

Figure 9: Minimum temperature anomaly under RCP 2.6 of wolikite.

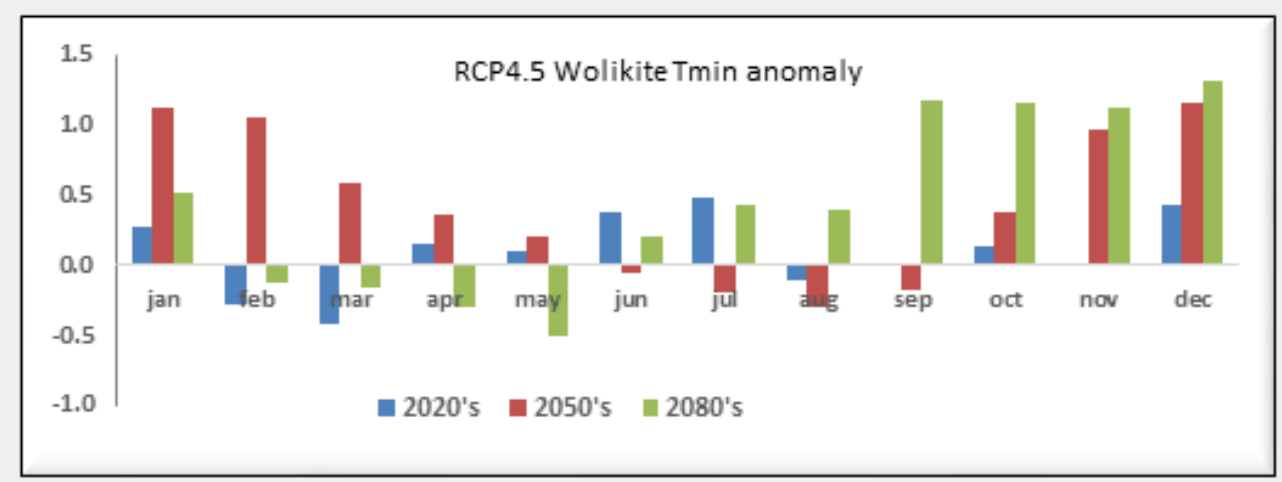

Figure 10: Minimum temperature anomaly under RCP 4.5 of wolikite.

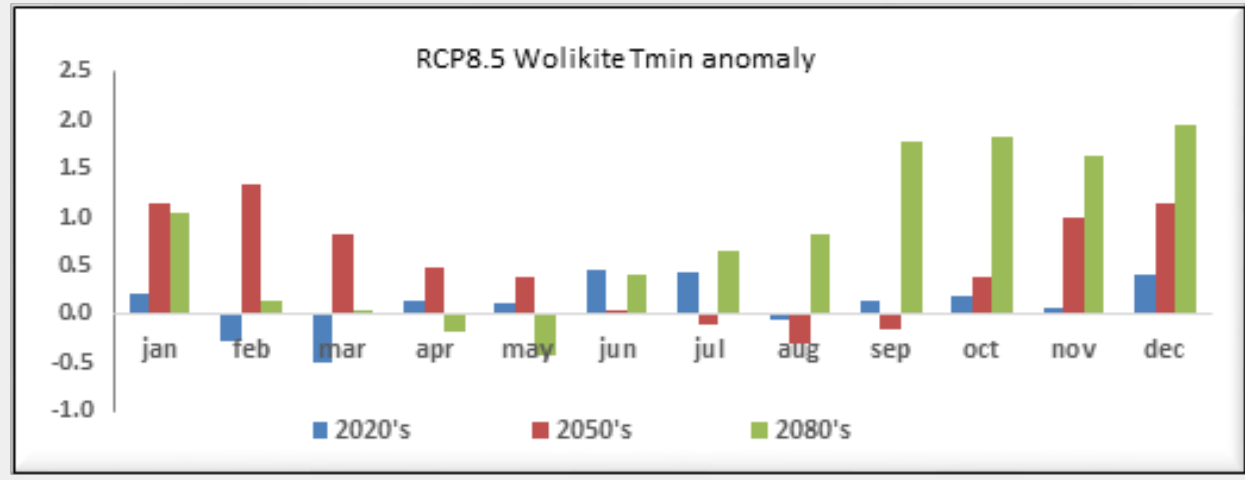

Figure 11: Minimum temperature anomaly under RCP 8.5 of wolikite.

\section{Maximum temperature Anomaly}

A positive anomaly indicates that the observed temperature was warmer than the long- term mean under RCP2.6 (Figure 12) below observed Tmax increase JJAS for all time horizon but for the 
rest months negative anomaly which indicates the observed Tmax is cooler than long term mean.

In Figure 13 below under RCP4.5 observed Tmax has positive anomaly for months JJAS for 2020's, 2050's and 2080's. While, a negative anomaly indicates that the observed temperature was cooler than the long- term mean value for months JFMA under intermediate emission scenarios and High emission scenarios Figure 14 below.

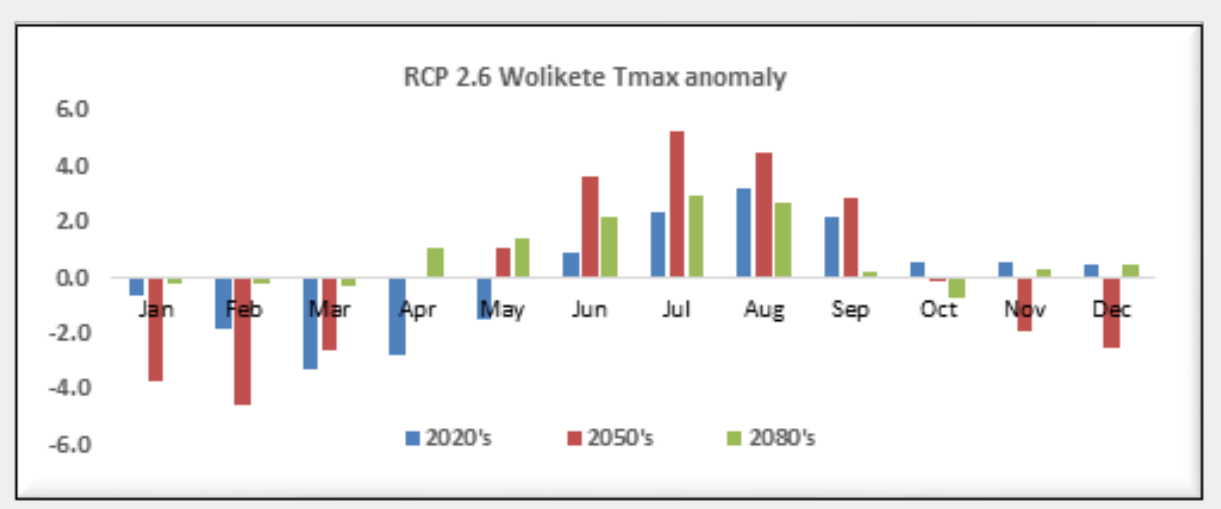

Figure 12: Maximum temperature anomaly under RCP 2.6 of wolikite.

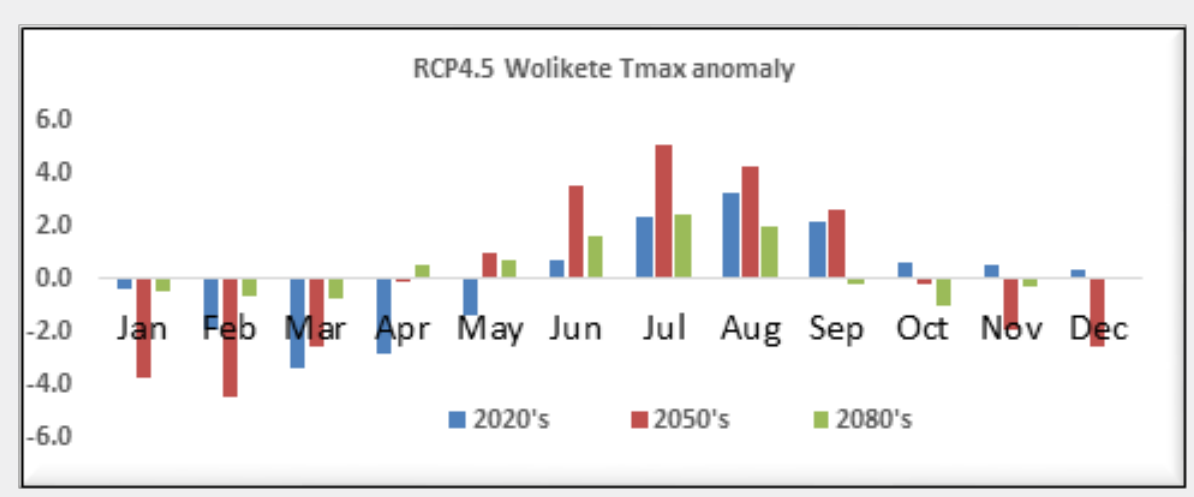

Figure 13: Maximum temperature anomaly under RCP 2.6 of wolikite.

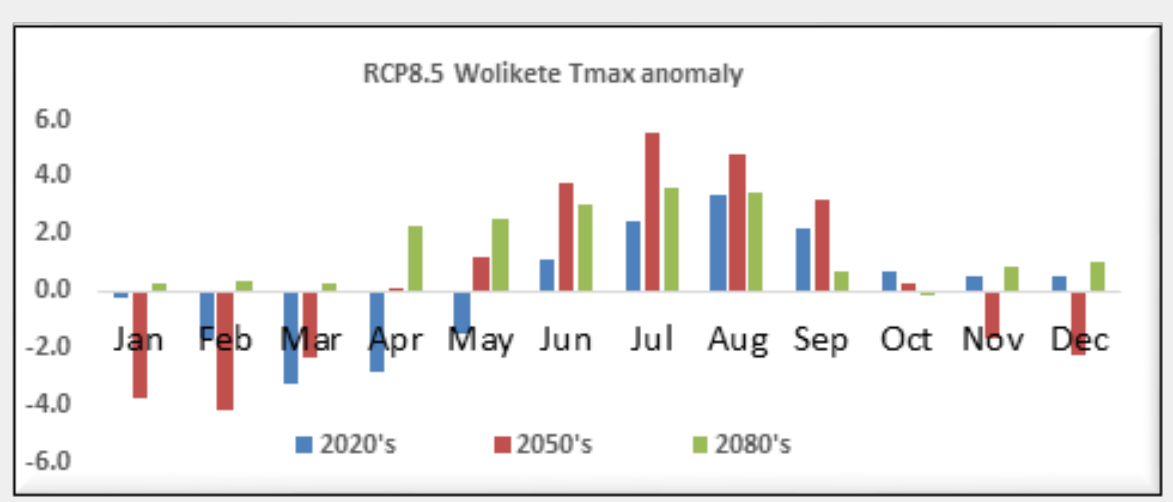

Figure 14: Maximum temperature anomaly under RCP 8.5 of wolikite.

\section{Precipitation anomaly}

In the Figure 15 below shows that under RCP 2.6 Positive anomaly for most of months which means the observed precipitation is above the long-term normal for those months, and the negative anomaly were only for few months (JJA) but for June the negative anomaly will be on 2050's time horizon. 


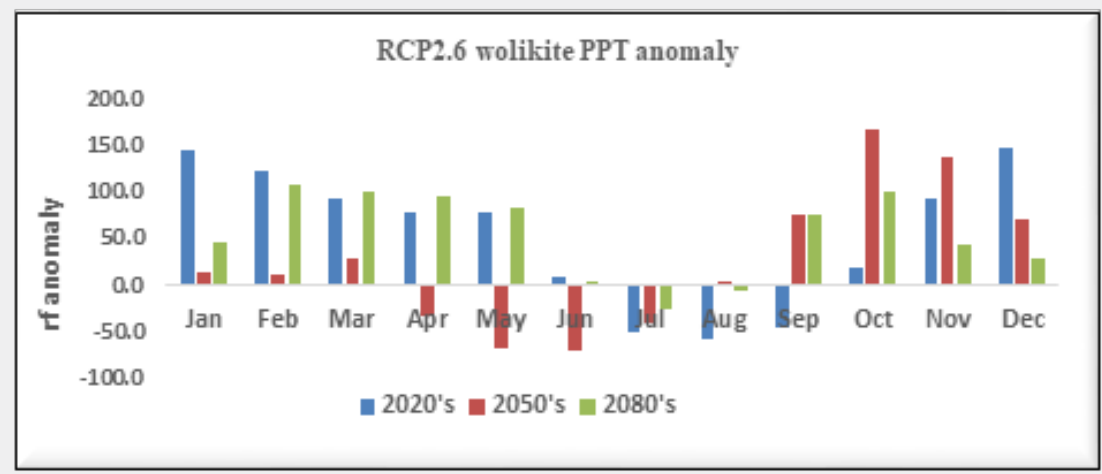

Figure 15: Precipitation anomaly under RCP 2.6 of wolikite.

Under emission scenario RCP 4.5 (Figure 16) below the negative anomaly was found only for June and July for all threetime horizons, for months August and September negative anomaly for 2020-time horizon. This is similar for emission scenario under RCP8.5 but the difference on percent of above normal and below normal (Figure 17) below.

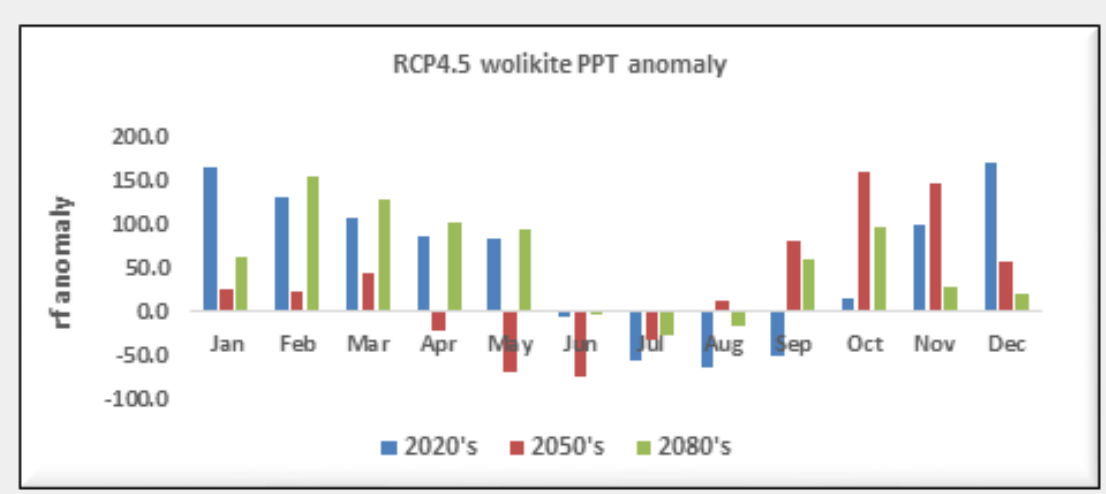

Figure 16: Precipitation anomaly under RCP 4.5 of wolikite.

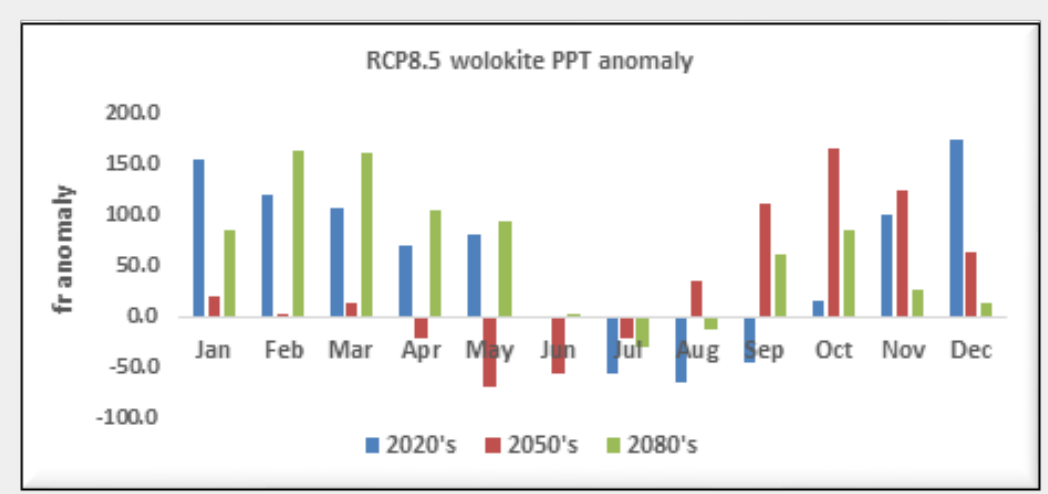

Figure 17: precipitation anomaly under RCP 8.5 of wolikite.

\section{Projected future climate variables (scenario generation)}

After tedious the calibration and validation of SDSM model, carried out, the daily future climate variables are projected for the next century using the CanESM2 Global Circulation Model. The projection generates 20 ensembles of daily climate variables, which are equally plausible; hence, these ensembles were averaged out in order to consider the characteristics of all those 20 ensembles. With the aid of statistical downscaling model the 
GCMs global predictors were used for development of future climate scenarios and the analysis was made for 2020s, 2050s and 2080s under RCP2.6, RCP4.5 and RCP8.5 (different representative concentration path way scenarios).

\section{Minimum temperature}

The downscaled minimum temperature shows an increasing trend in all future time horizons for RCP2.6, RCP4.5 and RCP8.5 scenarios for the stations. The downscaled minimum temperature in 2020s indicated that the minimum temperature will rise by $0.9^{\circ} \mathrm{C}$ under RCP2.6 scenarios. For the same time horizon under $\mathrm{RCP} 4.5$ scenario the minimum temperature will rise by $1.2^{\circ} \mathrm{C}$ for wolkite meteorological stations. Under RCP8.5 it will increased by $1.3^{\circ} \mathrm{C}$. In $2050 \mathrm{~s}$ the increment will be $4.6^{\circ} \mathrm{C}$ for the station. The increment will be expected to be high in $2080 \mathrm{~s}$, by $3.3^{\circ} \mathrm{C}, 5.3^{\circ} \mathrm{C}$ and $9^{\circ} \mathrm{C}$ under RCP2.6, RCP4.5 and RCP8.5 scenarios respectively.

\section{Maximum temperature}

Similar to projected average monthly minimum temperature, maximum temperature also reflects increasing trend in future climate periods. The projected maximum temperature in 2020s-time horizon indicated that maximum temperature would rise by $0.4^{\circ} \mathrm{C}, 0.8^{\circ} \mathrm{C}$ and $1.5^{\circ} \mathrm{C}$ under RCP2.6, RCP 4.5 and RCP 8.5 respectively. In 2050 s the increment will be $2.3^{\circ} \mathrm{C}$ under $\mathrm{RCP} 2.6,2.9^{\circ} \mathrm{C}$ under RCP4.5 and $3.9^{\circ} \mathrm{C}$ under RCP8.5 scenarios for Jimma station. The highest maximum temperature rise will be expected under RCP 2.6 by $2^{\circ} \mathrm{C}, \mathrm{RCP} 4.5$ by $3^{\circ} \mathrm{C}$ and RCP 8.5 by $4.6^{\circ} \mathrm{C}$ for Wolkite station. In $2080 \mathrm{~s}$ the maximum temperature will be increased by $7^{\circ} \mathrm{C}, 6^{\circ} \mathrm{C}$ and $8^{\circ} \mathrm{C}$ under RCP2.6, RCP 4.5 and RCP 8.5 scenario respectively. This shows that the future period will experience increasing trend in maximum temperature under all three representative concentration pathway scenarios. However, the increments will be less for RCP2.6 scenario relative to RCP8.5 scenario.

\section{Precipitation}

The projected mean annual precipitation in 2020s the stations were indicated that mean annual precipitation will decrease by $5 \%, 5.4 \%$ and 5\% under RCP2.6, RCP4.5 and RCP 8.5 respectively. In 2050 's the minimum decrement will be expected under RCP2.6 by $2.3 \%$, RCP 4.5 by $2.8 \%$ and RCP 8.5 by $3 \%$ for Wolkite station. In 2080 's time horizon the projected precipitation will be decreased by $5.9 \%$ under RCP2.6 scenario and under RCP4.5 scenario it will be decreased by $5.6 \%$. For the worst scenario (RCP8.5) the future precipitation will be expected to decrease by $5.9 \%$ for stations. Overall, the three scenarios of CanESM2 projected a lessening trend in the annual precipitation.

\section{Conclusion and Recommended}

The results of the climate projection showed that Statistical downscaling model is able to replicate the observed and simulated maximum and minimum temperature well; however, precipitation couldn't able to replicate well this is due its conditional nature and high variability in space and time.

The average annual minimum temperature will be increased by $3.3^{\circ} \mathrm{C}, 5.3^{\circ} \mathrm{C}$ and $9.0^{\circ} \mathrm{C}$ for $\mathrm{rcp} 2.6, \mathrm{rcp} 4.5$ and $\mathrm{rcp} 8.5 \mathrm{rcp}$ scenario respectively towards the end of this century. Similarly, annual maximum temperature will be $7.0^{\circ} \mathrm{C}, 6.0^{\circ} \mathrm{C}$, and $8.0^{\circ} \mathrm{C}$. This also will increase with from lowest to highest emission scenarios.

The ensemble models are broadly consistent in indicating the shortening the main rain seasons that means monomial rainfall shrinks and ranging from over eight months of rain to only three months (JAS) under all RCPs for all time horizon for Wolikite station which requires water harvesting, effective and efficient utilization of water resource and mitigation activities. The results from localities study used for different impact studies and development plan.

\section{References}

1. Wilby RL, Wigley TML (1997) Downscaling general circulation model output: a review of methods and limitations. Progress in Physical Geography 21(4): 530-548.

2. Fowler HJ, Blenkinsop S, Tebaldi C (2007) Linking climate change modelling to impacts studies: recent advances in downscaling techniques for hydrological modelling. International Journal of Climatology 27(12): 1547-1578.

3. Xu CY (1999) From GCMs to river flow: a review of downscaling methods and hydrologic modeling approaches. Progress in Physical Geography 23(2): 229-249.

4. Cuderlik JM (2007) Hydrologic models for inverse climate change impact Modeling, the $18^{\text {th }}$ Canadian Hydrological Conference on Challenges for water resource Engineering in a changing world, Manitoba.

5. Dibike YB, Coulibaly P (2005) Hydrologic impact of climate change in the Saguenay watershed: comparison of downscaling methods and hydrologic models. Journal of Hydrology 307(1-4): 145-163.

6. Ellis E (2011) Land-use and land-cover change. Encyclopedia of Earth.

7. McCarthy JJ, Canziani OF, Leary NA, Dokken DJ, White KS (2001) Climate change 2001: impacts, adaptation and vulnerability. Contribution of Working Group II to the Third Assessment Report of the Intergovernmental Panel on Climate Change. Cambridge Univ. Press, Cambridge, UK.

8. Houghton JT, Ding Y, Griggs DJ, Noguer M, vander Linden PJ, et al. (2001) Climate change 2001: the scientific basis. Contribution of Working Group I to the Third Assessment Report of the Intergovernmental Panel on Climate Change, Cambridge Univ. Press, Cambridge, UK.

9. Trenberth KE, Dai A, Rasmussen RM, Parsons DB (2003) The changing character of precipitation. Bull Am Meteorol Soc 84(9): 1205-1215.

10. Hengeveld H (2006) The science of changing climates. In: Bhatti JS, Lal R, Apps MJ, Price MA (Eds.), Climate change and managed ecosystems. CRC, Taylor and Francis, Boca Raton, FL, pp. 17-43.

11. New M, Todd M, Hulme M, Jones P (2001) Precipitation measurements and trends in the twentieth century. Int J Climatol 21(15): 1889-1922.

12. Frich P, Alexander LV, Della-Marta P, Gleason B, Haylock M, et al. (2002) Observed coherent changes in climatic extremes during the second half of the twentieth century. Clim Res 19: 193-212. 
13. Milly PC, Wetherald RT, Dunne KA, Delworth TL (2002) Increasing risk of great floods in a changing climate. Nature 415: 514-517.

14. Nakcenovic N, Swart R (2000) Special Report on Emissions Scenarios. A special report of Working Group III of the Intergovernmental Panel on Climate Change. Cambridge Univ. Press, Cambridge, UK.

15. van Vuuren DP, Edmonds J, Kainuma M, Riahi K, Thomson A, et al (2011) The representative concentration pathways: an overview. Climate Change 109(5).

16. Moss RH, Edmonds JA, Hibbard KA, Manning MR, Rose SK, et al. (2010) The next generation of scenarios for climate change research and assessment. Nature 463: 747-756.
17. SDSM 4.2 - A decision support tool for the assessment of regional climate change impacts SDSM user manual 2007.

18. Molla M (2016) Prediction of future climate and its impact on crop production and possible adaptation Strategy; SNNPR Shashogo woreda, Ethiopia.

19. Molla M (2016) Climate Variability, its impact on Maize Production and Adaptation options: Case Study of Halaba Special Woreda, Southern Ethiopia.

20.Wilby RL, Dawson CW (2007) Climate Change Unit, Environment Agency of England and Wales, Nottingham, NG2 5FA, UK, Department of Computer Science, Loughborough University, Leics, LE11 3TU, UK, p. 7.

\section{Your next submission with Juniper Publishers} will reach you the below assets

- Quality Editorial service

- Swift Peer Review

- Reprints availability

- E-prints Service

- Manuscript Podcast for convenient understanding

- Global attainment for your research

- Manuscript accessibility in different formats ( Pdf, E-pub, Full Text, Audio)

- Unceasing customer service

Track the below URL for one-step submission https://juniperpublishers.com/online-submission.php 